\title{
CORRELATION OF SIX-MINUTE WALK TEST AND COPD ASSESSMENT TEST (CAT) SCORES WITH SPIROMETRIC INDICES IN CHRONIC OBSTRUCTIVE PULMONARY DISEASE PATIENTS IN A TERTIARY CARE HOSPITAL IN CHENNAI
}

\author{
Vengada Krishnaraj S. P1, Anand Pugazhendhi², Vinod Kumar Viswanathan³, Sridhar Rathinam ${ }^{4}$ \\ ${ }^{1}$ Assistant Professor, Department of Tuberculosis and Respiratory Medicine, Government Stanley Medical College, Chennai. \\ ${ }^{2}$ Assistant Professor, Department of Tuberculosis and Respiratory Medicine, Government Thiruvannamalai Medical College, \\ Thiruvannamalai. \\ ${ }^{3}$ Associate Professor, Department of Tuberculosis and Respiratory Medicine, Government Stanley Medical College, Chennai. \\ ${ }^{4}$ Professor, Department of Tuberculosis and Respiratory Medicine, Government Stanley Medical College, Chennai.
}

\section{ABSTRACT}

\section{BACKGROUND}

Spirometric measurement of post-bronchodilator FEV1 is essential for establishing the diagnosis, assessment of severity, to predict the outcome and to assess response to treatment in COPD. Measurement of the walking distance is used to assess functional capacity of patients with COPD. Six-minute walk test (6MWT) is a simple, objective, and reproducible test. The facility of spirometry is not available in many rural areas of India because of lack of infrastructure where 6MWT can be done easily. The COPD assessment test (CAT) is a validated test for evaluation of COPD impact on health status. Therefore, in this study, we aim to find relationship between Six-minute walk test, Spirometry and COPD Assessment Test (CAT) scores in chronic obstructive pulmonary disease patients.

\section{MATERIALS AND METHODS}

Seventy-five patients of COPD were enrolled for the study after applying inclusion and exclusion criteria. The impact of COPD on health status was assessed using CAT score. All patients underwent spirometric measurement of FEV1, FVC, and ratio of FEV1 and FVC and test repeated after bronchodilation by 200-400 $\mu \mathrm{g}$ of salbutamol. 6MWT was performed following American Thoracic Society (ATS) protocol of 6MWT and distance was measured in metres. The results were analysed using SPSS software version 19.

\section{RESULTS}

We found significant linear correlation of 6MWD with post-FEV1( $r=0.561, \mathrm{P}<0.001)$, post-FVC $(\mathrm{r}=0.341, \mathrm{P}=0.003)$, and FEV1/FVC $(r=0.476, P<0.001)$. The mean CAT score was $20.49 \pm 5.34$ SD. There was a significant association between post-FEV1 and total CAT score $(\mathrm{P}<0.001)$. The correlation between mean post-FEV1 and mean score of CAT groups $1,2,3$, and 4 was statistically significant $(\mathrm{P}<0.001)$.

\section{CONCLUSION}

6MWT can be a useful replacement of spirometry in assessment of severity of COPD. The relationship between CAT score and postFEV1 suggests that CAT is linked to severity of airflow limitation and GOLD classification in stable COPD patients. Spirometry is not needed every time to assess the severity of COPD. However, Spirometry is necessary to diagnose COPD. CAT score can be used to assess the impact of COPD on health status and quality of life. Both 6MWT and CAT score can be used even in a rural setting where most of the COPD patients have no access to spirometry.

\section{KEYWORDS}

Chronic Obstructive Pulmonary Disease (COPD), Spirometry, Six-minute Walk Test (6MWT), CAT Score.

HOW TO CITE THIS ARTICLE: Krishnaraj VSP, Pugazhendhi A, Viswanathan VK, et al. Correlation of six-minute walk test and COPD assessment test (CAT) scores with spirometric indices in chronic obstructive pulmonary disease patients in a tertiary care hospital in Chennai. J. Evolution Med. Dent. Sci. 2017;6(70):4983-4986, DOI: 10.14260/Jemds/2017/1082

\section{BACKGROUND}

Chronic obstructive pulmonary disease (COPD) comprises of two diseases namely chronic bronchitis and emphysema. It is a common, preventable and treatable disease that is characterised by persistent respiratory symptoms and airflow limitation that is due to airway and/or alveolar abnormalities usually caused by significant exposure to noxious particles or gases. ${ }^{1}$

Financial or Other, Competing Interest: None.

Submission 10-08-2017, Peer Review 23-08-2017,

Acceptance 26-08-2017, Published 31-08-2017.

Corresponding Author:

Dr. Anand Pugazhendhi,

Assistant Professor,

Department of Tuberculosis and Respiratory Medicine,

Government Thiruvannamalai Medical College,

Thiruvannamalai.

E-mail: anand.neduman@gmail.com

DOI: $10.14260 /$ jemds $/ 2017 / 1082$
Exacerbations and comorbidities contribute to the overall severity in individual patients. The global prevalence of COPD is approximately 9-10 percent. ${ }^{2}$ According to INSEARCH study, in India, COPD prevalence among men is 9.02 million and among women is 5.75 million. ${ }^{3}$

Spirometry is essential for establishing the diagnosis, assessment of severity, to predict the outcome and to assess response to treatment in Chronic obstructive pulmonary disease (COPD). ${ }^{1}$ Measurement of the walking distance is used to assess functional capacity of patients of COPD. Sixminute walk test (6MWT) is a simple, objective and reproducible test. ${ }^{4}$ The facility of spirometry is not available in many rural areas of India because of lack of infrastructure where 6MWT can be done easily. The COPD assessment test (CAT) is a validated test for evaluation of COPD impact on health status. ${ }^{5}$ Therefore, in this study, we aim to correlate between Six-minute walk test, Spirometry and COPD 
Assessment Test (CAT) scores in chronic obstructive pulmonary disease patients.

\section{Aim}

To study the correlation between Six-minute walk test, Spirometry and COPD Assessment Test (CAT) Scores in chronic obstructive pulmonary disease patients.

\section{Objective}

To study whether Six-minute walk test and CAT Score can be used as an alternative to spirometry in resource-poor settings to predict the severity of COPD.

\section{Site of Investigation}

Govt. Hospital of Thoracic Medicine, Tambaram Sanatorium, Chennai.

\section{Study Period}

October 2015 to July 2016.

\section{Study Design}

Prospective observational study.

\section{Study Population}

Outpatients and Inpatients of Government Hospital of Thoracic Medicine, Tambaram Sanatorium, Chennai.

\section{Sample Size- 75.}

\section{Inclusion Criteria}

a. Patients who were diagnosed as COPD by GOLD criteria.

b. Age $\geq 40$ years.

\section{Exclusion Criteria}

a. Patients with comorbid conditions like Diabetes Mellitus, Systemic hypertension, Pulmonary hypertension, Corpulmonale, Coronary heart disease, Ischaemic heart disease.

b. Active pulmonary tuberculosis.

c. Treated pulmonary and extrapulmonary tuberculosis patients.

d. Patients with associated neurological disease.

e. Patients with associated rheumatologic disease.

f. Patients with acute exacerbation of COPD.

g. Patients with peripheral vascular disease.

h. Patients who use Non-invasive ventilation.

i. Patients who are not willing to participate.

\section{MATERIALS AND METHODS}

\section{Procedure}

1. Patients were selected after applying inclusion and exclusion criteria. Informed written consent was obtained from the patients. Entire procedure was explained to them clearly.

2. A CAT respiratory questionnaire in Tamil version was given to all patients and were asked to mark their symptoms scoring. The total CAT score of each patient was calculated and recorded.

3. In all patients, airflow limitation was measured as per ATS recommendations.

4. Spirometry was done and $\mathrm{FEV}_{1}, \mathrm{FVC}$ and ratio of $\mathrm{FEV}_{1}$ / FVC were measured. Then, the patients were given 200-400 micrograms of salbutamol. After 15 minutes, spirometry was done again. Post-bronchodilator FEV FVC and $\mathrm{FEV}_{1} / \mathrm{FVC}$ ratio were measured.

5. 6-minute walk test (6MWT) was performed according to ATS guidelines. ${ }^{4}$ Before the test, heart rate, blood pressure, and $\mathrm{SpO} 2$ measurements were done. Emergency resuscitation measures were kept ready to treat the patients, in case any complications develop during the procedure. Patients were made to walk along a 30-metre long path marked at intervals of one metre each. They were allowed to walk at their own pace. If the patient develops any symptom of chest pain, severe dyspnoea, or leg pain, they were allowed to rest during the test. Then, they were allowed to continue. The patients were encouraged to complete the test.

6. The patients were asked to stop after 6 minutes. After the test was over, heart rate, blood pressure and SpO2 measurements were done again. Distance walked by the patient at the end of 6 minutes was recorded in metres.

7. For each patient, points obtained in CAT Score, Spirometric indices $\left(\mathrm{FEV}_{1}, \mathrm{FVC}, \mathrm{FEV}_{1} / \mathrm{FVC}\right)$ and the distance walked in Six-minute walk test were compared and analysed using SPSS software version 19 . The data were reported as mean \pm standard deviation (SD). The correlation between 6MWD and spirometric indices were evaluated using Pearson's correlation coefficient. One way ANOVA was used to study the relationship between the 6MWD results and the severity of COPD stages based on the measured FEV1. The correlation between the CAT score and GOLD classification was also evaluated by Pearson's correlation coefficient.

\section{Ethical Justification}

The various investigations and procedures that were used in this study were as per protocol and were approved from ethical committee. The identity of each patient was kept confidential. This study did not violate medical ethics in anyway and it was meant to know the relationship between Six-minute walk test, Spirometry and COPD Assessment Test (CAT) scores in chronic obstructive pulmonary disease patients.

\section{RESULTS}

Total number of 75 patients were enrolled in this study, of which females were $13.3 \%$ and males were $86.7 \%$ (Table 1 ).

\begin{tabular}{|c|c|c|c|}
\hline $\begin{array}{c}\text { Age Distribution } \\
\text { in Years }\end{array}$ & Male (\%) & Female (\%) & Total (\%) \\
\hline $40-44$ & $3(4)$ & $1(1.3)$ & $4(5.3)$ \\
\hline $45-49$ & $6(8)$ & $2(2.7)$ & 8 (10.7) \\
\hline $50-54$ & $3(4)$ & $1(1.3)$ & $4(5.3)$ \\
\hline 55-59 & $12(16)$ & $2(2.7)$ & $14(18.7)$ \\
\hline$>60$ & $41(54.7)$ & $4(5.3)$ & $45(60)$ \\
\hline Total & $65(86.7)$ & $10(13.3)$ & $75(100)$ \\
\hline
\end{tabular}

CAT questionnaire was given to all these patients and CAT score was calculated. Then, spirometry was done according to GOLD criteria. 


\begin{tabular}{|c|c|c|c|}
\hline $\begin{array}{c}\text { Severity of } \\
\text { Symptoms }\end{array}$ & FEV $\mathbf{1} \%$ & $\begin{array}{c}\text { Number of } \\
\text { Patients }\end{array}$ & Percentage \\
\hline Mild (Stage I) & $>80$ & 4 & 5.3 \\
\hline Moderate (Stage II) & $50-80$ & 18 & 24 \\
\hline Severe (Stage III) & $30-50$ & 42 & 56 \\
\hline $\begin{array}{c}\text { Very Severe (Stage } \\
\text { IV) }\end{array}$ & $<30$ & 11 & 14.7 \\
\hline \multicolumn{2}{|c|}{ Table 2. GOLD Staging of the Study Population } \\
\hline
\end{tabular}

In Table 2, we can see that 4 patients are grouped in Stage I, 18 patients are grouped in Stage II, 42 patients are grouped in Stage III and 11 patients are grouped in Stage IV.

\begin{tabular}{|c|c|c|c|c|}
\hline & Gold I & Gold II & Gold III & Gold IV \\
\hline $\begin{array}{c}\text { Number of } \\
\text { patients }\end{array}$ & 4 & 18 & 42 & 11 \\
\hline CAT score & $10.25 \pm$ & $19.55 \pm$ & $21.04 \pm$ & $23.63 \pm$ \\
(Mean \pm SD) & 0.95 & 5.42 & 4.76 & 3.47 \\
\hline Table 3. Correlation between the Number of Patients in \\
Various GOLD Stages and their Mean CAT Score \\
\hline
\end{tabular}

$\mathrm{p}$ value $<0.001$
4 patients in Stage I had a mean CAT score of $10.25 \pm 0.95$. 18 patients in Stage II had a mean CAT score of $19.55 \pm 5.42$. 42 patients in Stage III had a mean CAT score of $21.04 \pm 4.76$. 11 patients in Stage IV had a mean CAT score of $23.63 \pm 3.47$.

In all these patients, Six-minute walk test (6MWT) was performed. Distance covered by the patients (6MWD) was measured and correlated with different parameters of spirometry.

\begin{tabular}{|c|c|c|c|}
\hline $\begin{array}{c}\text { Severity of } \\
\text { Symptoms }\end{array}$ & FEV $_{\mathbf{1}} \%$ & $\begin{array}{c}\text { Number of } \\
\text { Patients }\end{array}$ & 6MWD \\
\hline Mild (Stage I) & $>80$ & 4 & $\begin{array}{c}482.5 \pm 11.9 \\
\text { metres }\end{array}$ \\
\hline Moderate (Stage II) & $50-80$ & 18 & $\begin{array}{c}429.8 \pm 76.6 \\
\text { metres }\end{array}$ \\
\hline Severe (Stage III) & $30-50$ & 42 & $\begin{array}{c}360.5 \pm 80.3 \\
\text { metres }\end{array}$ \\
\hline $\begin{array}{c}\text { Very Severe (Stage } \\
\text { IV) }\end{array}$ & $<30$ & 11 & $\begin{array}{c}293.3 \pm 84.4 \\
\text { metres }\end{array}$ \\
\hline \multicolumn{4}{|c|}{ F -Ratio $=9.905$, p<0.001 } \\
\hline \multicolumn{4}{|c|}{ Table 4. 6MWD by Patients in Different Stages } \\
\hline
\end{tabular}

\begin{tabular}{|c|c|c|c|c|c|}
\hline 6MWD (Metres) & I (\%) & II (\%) & III (\%) & IV (\%) & Total (\%) \\
\hline $101-200$ & $0(0)$ & $0(0)$ & $1(1.3)$ & $1(1.3)$ & $2(2.7)$ \\
\hline $201-300$ & $0(0)$ & $1(1.3)$ & $7(9.3)$ & $6(8)$ & $14(18.7)$ \\
\hline $301-400$ & $0(0)$ & $5(6.7)$ & $25(33.3)$ & $4(5.3)$ & $34(45.3)$ \\
\hline$>401$ & $4(5.3)$ & $12(16)$ & $9(12)$ & $0(0)$ & $25(33.3)$ \\
\hline Total (\%) & $4(5.3)$ & $18(24)$ & $42(56)$ & $11(14.7)$ & $75(100)$ \\
\hline
\end{tabular}

\begin{tabular}{|c|c|c|c|c|}
\hline & \multicolumn{4}{|c|}{ Six-minute walk test (metres) } \\
\hline & Range & Mean \pm SD & Pearson correlation & P value \\
\hline Post FEV1 & $18.1-83$ & $43.69 \pm 15.12$ & 0.561 & $<0.001$ \\
\hline Post FVC & $30.6-95$ & $59.48 \pm 15.65$ & 0.341 & 0.003 \\
\hline Post FEV 1 FVC & $0.28-0.77$ & $0.56 \pm 0.11$ & 0.476 & $<0.001$ \\
\hline \multicolumn{7}{|c|}{ Table 6. Correlation between 6MWD with Spirometric Indices } \\
\hline
\end{tabular}

\section{DISCUSSION}

In our study, there is a positive correlation of 6MWD with post FEV 1 \& FVC. In Table 4, among 75 patients, 6MWD of 4 patients in stage I GOLD classification was $482.5 \pm 11.9$ metres. 6MWD of 18 patients in stage II GOLD classification was $429.8 \pm 76.6$ metres. 6 MWD of 42 patients in stage III was $360.5 \pm 80.3$ metres. $6 \mathrm{MWD}$ of 11 patients in stage IV was $293.3 \pm 84.4$ metres. $\mathrm{P}$ value $<0.001$ (statistically significant).

Post-bronchodilator $\mathrm{FEV}_{1}$ was compared with 6MWD (Table 6). We got Pearson correlation as 0.561 and a $\mathrm{P}$ value of < 0.001 which is statistically significant. It shows a positive correlation between $\mathrm{FEV}_{1}$ and 6MWD. Similarly, postbronchodilator FVC was compared with 6MWD (Table 6). We got Pearson correlation as 0.341 and a $P$ value of 0.003 which is statistically significant. It shows a positive correlation between FVC and 6MWD. Also, Post-bronchodilator $\mathrm{FEV}_{1}$ /FVC was compared with 6MWD, we got a Pearson correlation as 0.476 and $P$ value $<0.001$ (Table 6). It is compatible with the study published by Chulmsky et al. ${ }^{6}$
Our study is compatible with studies of Roozbeh et al, ${ }^{7}$ Mehta and Kumari et $\mathrm{al}^{8}$ and Carter et $\mathrm{al}^{9}$ which also showed association between 6MWT and expiratory volumes in COPD.

As shown in Table 3, we find a positive correlation between severity of COPD and CAT score with a $\mathrm{P}$ value $<0.001$. Scores increase as the stage increases i.e. patients with more severe COPD had higher CAT scores. It is compatible with the study by Jones PW et al,10 which analysed the properties of CAT Score in a cross-sectional European study.

\section{Limitations}

a) Our sample size was small.

b) Only $13.3 \%$ of our study population were female. So we could not find out the exact correlation in female population.

c) 6 MWT may be affected by a variety of factors like age, sex, height and weight. We did not adjust these parameters while calculating 6 MWD. 


\section{CONCLUSION}

People with COPD are affected socially and economically. So it is necessary to diagnose COPD early and assess the disease severity and treat it appropriately. In COPD, the disease severity is usually assessed by the post-bronchodilator FEV1 done by using spirometry. But spirometry has its own disadvantages. It is effort-dependent and many times it may not give the correct reading if the patient does not blow properly. Patients need a little extra effort to do the test. They generally do not understand the science behind it. Spirometry test is also costly. It is beyond the reach of patients who are economically backward and who are treated by primary care physicians.

From this study, we conclude that 6-minute walk test can be used as an alternate tool to assess the severity of COPD. Spirometry is not needed every time to assess the severity of COPD. However, Spirometry is necessary to diagnose COPD. CAT score can be used to assess the impact of COPD on health status and quality of life. Both 6MWT and CAT score can be used even in a rural setting where most of the COPD patients have no access to spirometry.

\section{REFERENCES}

[1] Global Initiative for Chronic Obstructive Lung Disease (GOLD). Global Strategy for the Diagnosis, Management and Prevention of COPD. 2017.

[2] Halbert R J, Natoli JL, Gano A, et al. Global burden of COPD: systematic review and meta-analysis. Eur Respir Journal 2006;28(3):523-32.
[3] Mahesh PA, Jayaraj BS, Prahlad ST, et al. Validation of a structured questionnaire for COPD and prevalence of COPD in rural area of Mysore: a pilot study. Lung India 2009;26(3):63-9.

[4] ATS Committee on Proficiency Standards for Clinical Pulmonary Function Laboratories. ATS statement: guidelines for the six-minute walk test. Am J Respir Crit Care Med 2002;166(1):111-7.

[5] Jones PW, Tabberer M, Chen WH. Creating scenarios of the impact of COPD and their relationship to COPD Assessment Test (CAT ${ }^{\mathrm{TM}}$ ) scores. BMC Pulm Med 2011;11:42.

[6] Chlumsky J, Sterbova L, Smolikova L, et al. Relation between pulmonary ventilation parameters, exercise tolerance and quality of life in patients with chronic obstructive lung disease. Vnitr Lek 2002;48(4):320-4.

[7] Roozbeh N, Mohammad MZ, Amin EA. Association between six-minute walk test and expiratory spirometry parameters in chronic obstructive pulmonary disease. Iranian Heart J 2005;6:59-63.

[8] Mehta A, Kumari IK. Correlation of Six-minute walk test with spirometry and DLCO in chronic respiratory diseases. Pulmon 2011;13:55-9.

[9] Carter R, Holiday DB, Nwasuruba C, et al. 6-minute walk work for assessment of functional capacity in patients with COPD. Chest 2003;123(5):1408-15.

[10] Jones PW, Brusselle G, Negro DRW, et al. Properties of the COPD assessment test in a cross-sectional European study. Eur Respir J 2011;38(1):29-35. 